\title{
ANOMALOUS SORPTION OF NEODYMIUM AND PRASEODYMIUM IONS BY INTERGEL SYSTEM POLYACRYLIC ACID HYDROGEL - POLY-4-VINYLPYRIDINE HYDROGEL
}

\author{
Talkybek Jumadilov ${ }^{1}$, Ruslan Kondaurov ${ }^{1,} \otimes$, Aldan Imangazy ${ }^{1}$, \\ Khuangul Khimersen ${ }^{2}$, Zamira Malimbayeva ${ }^{3}$
}

https://doi.org/10.23939/chcht16.01.007

\begin{abstract}
This paper is devoted to study of sorption properties (sorption degree, polymer chain binding degree) of intergel system hydrogel of polyacrylic acid (hPAA) hydrogel of poly-4-vinylpyridine (hP4VP) in relation to neodymium and praseodymium ions. It was found that remote interaction of the polymers in intergel pairs provides significant changes of the electrochemical and volume gravimetric properties. Strong increase of the swelling degree of hPAA is observed at the ratio $17 \% \mathrm{hPAA}-$ $83 \% \mathrm{hP} 4 \mathrm{VP}$; significant increase of swelling degree of hP4VP is observed at the ratio $83 \% \mathrm{hPAA}-17 \% \mathrm{hP} 4 \mathrm{VP}$. Individual hydrogels of PAA and P4VP do not have sufficiently high sorption properties - sorption degree of neodymium and praseodymium ions is not higher than $65 \%$, polymer chain binding degree is not higher than $55 \%$. High ionization of hPAA and hP4VP due to remote interaction effect provides significant increase (up to $30 \%$ ) of the sorption properties. Maximum sorption of neodymium and praseodymium ions occurs at the ratios $83 \% \mathrm{hPAA}-17 \% \mathrm{hP} 4 \mathrm{VP}$ and $50 \% \mathrm{hPAA}-50 \% \mathrm{hP} 4 \mathrm{VP}$ (sorption degree is $93.5 \%$ and $93.6 \%$, respectively). The highest values of polymer chain binding degree (in relation to neodymium and praseodymium ions) are observed at the ratios $83 \% \mathrm{hPAA}-17 \% \mathrm{hP} 4 \mathrm{VP}$ and $50 \% \mathrm{hPAA}-50 \% \mathrm{hP} 4 \mathrm{VP}-$ binding degree is $73.2 \%$ and $75.4 \%$, respectively. Remote interaction provides possibilities for creation of innovative sorption technologies for selective sorption of aimed rareearth elements.
\end{abstract}

Keywords: intergel system, polyacrylic acid, poly-4vinylpyridine, remote interaction, $\mathrm{Nd}^{3+}$ and $\operatorname{Pr}^{3+}$ ions sorption.

\footnotetext{
${ }^{1}$ JSC "Institute of Chemical Sciences after A.B. Bekturov" 106, Sh. Valikhanov St., 050010 Almaty, the Republic of Kazakhstan

${ }^{2}$ Abai Kazakh National Pedagogical University

13, Dostyk ave., 050010 Almaty, the Republic of Kazakhstan

${ }^{3}$ Kazakh National Women's Teacher Training University

99, Aiteke Bi St., 050000 Almaty, the Republic of Kazakhstan

r-kondaurov@mail.ru

(c) Jumadilov, T.; Kondaurov, R.; Imangazy, A.; Khimersen, Kh.;

Malimbayeva, Z., 2022
}

\section{Introduction}

Ion-exchange processes are used for separation and purification of metals, including the separation of uranium from plutonium and other actinides, as well as lanthanum, thorium; neodymium, ytterbium, samarium, and lutetium from each other and from other lanthanides. ${ }^{1-5}$ There are two rows of rare-earth metals (REM): lanthanoides and actinoides. The metals from each row have similar physical and chemical properties. For many years, ion exchange was practically the only way to separate rareearth metal ions in large quantities. This use of resins was developed in 1940 by F. Spading. Subsequently, solvent extraction was mainly superseded by the use of ionexchange resins, except in cases involving the production of high purity products.

Wide application of ion-exchangers in hydrometallurgy, chemical technology and other areas began after creation of ion-exchange synthetic resins. Ionexchangers, which are produced nowadays, have high capacity, chemical resistance, mechanical strength, displaced other ion-exchange materials. ${ }^{6-13}$

The process of sorption of the aimed metal by the ion-exchange resin is presented in Fig. 1.

Ion-exchangers are also primary components at uranium mining when using underground leaching method. Underground leaching involves the extraction of uraniumbearing water through boreholes. The leach solution containing uranium is then passed through resins. Granules of resin remove uranium from solution by ion exchange.

The process of ion-exchange uranium extraction is based on the ability of ion-exchange resins to selectively and quantitatively absorb uranium from solutions and pulps after leaching. In sulfuric acid solutions, hexavalent uranium can be present in the form of a uranyl cation $\left(\mathrm{UO}_{2}{ }^{2+}\right)$ and anionic sulfate complexes, which are in dynamic equilibrium with each other:

$$
\mathrm{UO}_{2}{ }^{2+}+\mathrm{nSO}^{2-} \leftrightarrow \mathrm{UO}_{2}\left(\mathrm{SO}_{4}\right)_{\mathrm{n}}{ }^{2-2 \mathrm{n}}
$$

where $n=1,2$ or 3 . 

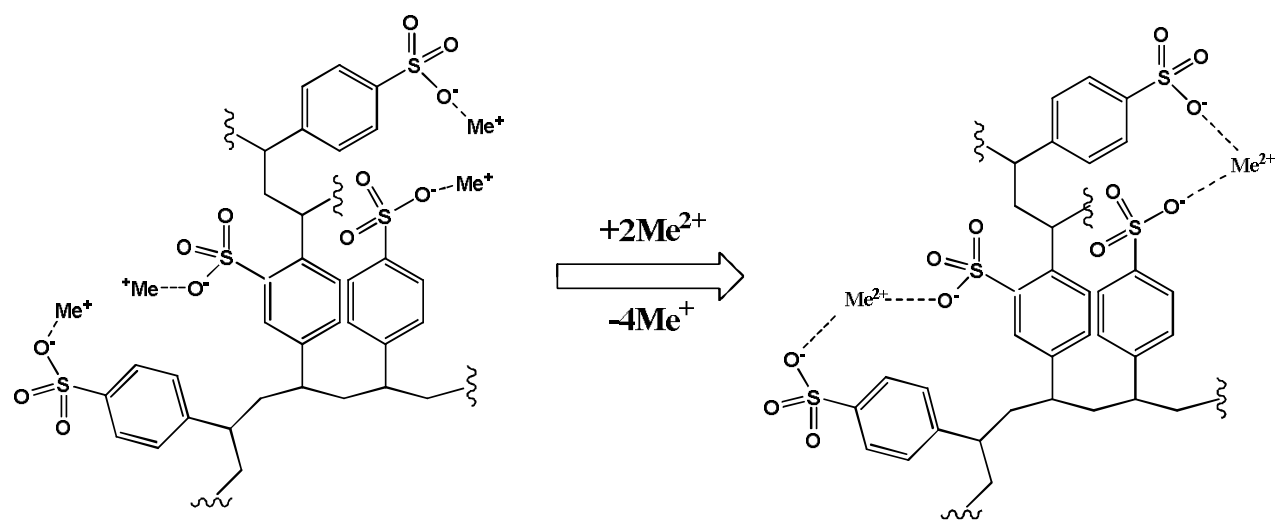

Fig. 1. Sorption of aimed metal by ion-exchange resin

After sulfuric acid leaching, uranium can be extracted from solutions and pulps using cationic or anion-exchange resins.

Ion exchange extraction of uranium in general is determined by the following reactions:

1) absorption of uranium by cation exchange resin:

$$
2 \mathrm{R}^{-} \mathrm{H}^{+}+\mathrm{UO}_{2}{ }^{2+} \leftrightarrow\left(\mathrm{R}^{-}\right)_{2} \mathrm{UO}_{2}{ }^{2+}+2 \mathrm{H}^{+}
$$

2) absorption of uranium by anioin exchange resin:

$$
\text { 3) }
$$

$$
\begin{aligned}
& 4 \mathrm{R}^{+} \mathrm{X}^{-}+\mathrm{UO}_{2}\left(\mathrm{SO}_{4}\right)_{3}{ }^{4-} \leftrightarrow\left(\mathrm{R}^{+}\right)_{4}\left[\mathrm{UO}_{2}\left(\mathrm{SO}_{4}\right)_{3}\right]^{4-}+4 \mathrm{X}^{-} \\
& 2 \mathrm{R}^{+} \mathrm{X}^{-}+\mathrm{UO}_{2}\left(\mathrm{SO}_{4}\right)_{2}{ }^{2-} \leftrightarrow\left(\mathrm{R}^{+}\right)_{2}\left[\mathrm{UO}_{2}\left(\mathrm{SO}_{4}\right)_{2}\right]^{2-}+2 \mathrm{X}^{-}
\end{aligned}
$$

where $\mathrm{R}$ - fixed ions of resin; $\mathrm{X}-\mathrm{NO}_{3}{ }^{-}, \mathrm{Cl}^{-}$.

Resins containing uranium are transported to a processing plant, where $\mathrm{UO}_{2}$ is separated from the resin granules and subsequently yellow cake is produced. After that, the resin, if necessary, undergoes regeneration, and is sent to re-extract uranium from the leach solution.

In recent years, worldwide demand for rare-earth metals has increased significantly. This is primarily due to their ever-increasing role in the leading industries, on which the economic and defense security of any state depends. In particular, as foreign experience shows, the use of high-quality low-alloy niobium and rare-earth steels gives the greatest effect in transport engineering, gas and oil industries and related piping systems, in the construction of large engineering structures, nuclear power facilities, and other important industries.

Previous investigations were devoted to study of hydrogels mutual activation. ${ }^{14-19}$ Polymer hydrogels usually are considered as smart materials, and their progressive functions are developing. In particular, different biomimetics and membrane applications are discussed widely in current literature..$^{20-22}$ In the result of these studies it was found that hydrogels remote interaction provides significant changes of their electrochemical and conformational properties. Further investigations were devoted to study of influence of different factors on polymer hydrogels remote interaction in intergel systems. ${ }^{23-27}$

In this regard the goal of the work is to study sorption ability of intergel system hPAA-hP4VP in relation to neodymium and praseodymium ions.

\section{Experimental}

\subsection{Equipment}

Specific electric conductivity of solutions was measured on conductometer "MARK-603" (Russia), hydrogen ions concentration was determined on $\mathrm{pH}$-meter Metrohm-827 (Switzerland). Mass of the hydrogels was measured on analytical scales SHIMADZU AY220 (Japan). Measurement errors do not exceed $1 \%$. Spectrophotometers Jenway-6305 (UK) and KFK-3M (Russia) were used for measurement of $\mathrm{Nd}^{3+}$ and $\mathrm{Pr}^{3+}$ ions concentration in solution.

\subsection{Materials and Methods}

Studies were carried out in $0.005 \mathrm{M}$ solutions of corresponding salts (neodymium and praseodymium nitrates). Hydrogels of polyacrylic acid (hPAA) were synthesized in the presence of crosslinking agent $\mathrm{N}, \mathrm{N}$ methylene-bis-acrylamide and redox system $\mathrm{K}_{2} \mathrm{~S}_{2} \mathrm{O}_{8}$ $\mathrm{Na}_{2} \mathrm{~S}_{2} \mathrm{O}_{3}$ in an aqueous medium. Synthesized hydrogels were crushed into small dispersions and continuously washed with distilled water until a constant conductivity value of aqueous solutions appeared. Poly-4-vinylpyridine hydrogel (hP4VP) was synthesized by Sigma-Aldrich company (linear polymer crosslinked with divinylbenzene).

For sorption studies from synthesized hydrogels intergel pairs hPAA-hP4VP were created. Swelling degrees of hydrogels are: $\alpha(\mathrm{hPAA})=27.99 \mathrm{~g} / \mathrm{g}, \alpha(\mathrm{hP} 4 \mathrm{VP})=$ $=3.35 \mathrm{~g} / \mathrm{g}$. With the increase of hP4VP share in intergel system the hPAA concentration decreased from 5.97 to 
$0.98 \mathrm{mmol} / \mathrm{L}$. Concentration of hP4VP with the decrease of hPAA increased from 0.99 to $5.99 \mathrm{mmol} / \mathrm{L}$.

Experiments were carried out at room temperature. Studies of intergel system were as following: each hydrogel in dry initial state was put in glass filter, pores of which are permeable to low molecular ions but nonpermeable to hydrogel dispersion. Electric conductivity and $\mathrm{pH}$ of solutions were measured in the presence of hydrogels. Swelling coefficient was estimated by Eq. (5):

$$
\alpha=\frac{m_{2}-m_{1}}{m_{1}}
$$

where $m_{1}$ and $m_{2}$ are masses of dry and swollen hydrogel, respectively, $\mathrm{g}$.

After that, filters with hydrogels were put into the salt solutions. After that, aliquots were gathered for further determination of concentration of the metals.

\subsection{Methodology of Neodymium and Praseodymium Ions Determination}

Methodology of the REM ions determination is based on formation of colored complexed compound of organic analytic reagent Arsenazo III with lanthanum ions. ${ }^{28}$

Extraction (sorption) degree was calculated by Eq.

$$
\eta=\frac{C_{\text {initial }}-C_{\text {residual }}}{C_{\text {initial }}} \cdot 100 \%
$$

where $C_{\text {initial }}$ and $C_{\text {residual }}$ are initial and residual concentrations of lanthanum in solution, respectively, $g / L$.

Polymer chain binding degree was determined by calculations in accordance with Eq. (7):

$$
\theta=\frac{V_{\text {sorbed }}}{V} \cdot 100 \%
$$

where $V_{\text {sorbed }}$ is a quantity of polymer links with sorbed lanthanum, mol; $V$ is total quantity of polymer links (if there are 2 hydrogels in solution, it is calculated as sum of each polymer hydrogel links), mol.

\section{Results and Discussion}

When put in water medium both hydrogels begin to swell as the result of interaction with water molecules. Carboxyl groups are firstly ionized and after that they dissociate on carboxylate anions $-\mathrm{COO}^{-}$and hydrogen ions (protons) $\mathrm{H}^{+}$. Ionization of cationic hydrogel poly-4vinylpyridine in an aqueous medium occurs in the result of accession of hydrogen ions formed at carboxyl groups dissociation and water molecules of ions $\mathrm{H}^{+}, \mathrm{OH}^{-}$. Hydrogels long-range effect provides the decrease of positive charges in an aqueous medium. Main reason of this phenomenon is conformational changes of links in internode chains. At certain concentrations charged $\mathrm{NH}^{+}$ groups may form intramolecular crosslinks $\geq \mathrm{N} . . . \mathrm{H}^{+} \ldots \mathrm{N} \equiv$, which provide folding of macromolecular globes and decrease of proton binding.

There is an excess of $\mathrm{H}^{+}$ions due to high rate of swelling and dissociation of $-\mathrm{COOH}$ groups and low swelling rate of basic groups and their low concentration. Increase of $\mathrm{OH}^{-}$ions quantity in water medium is due to low swelling speed and interaction of basic functional groups with protons. It is possible in case of occurrence of the ionization and partial dissociation of nitrogen heteroatom in pyridine ring in the result of what hydroxyl anions are released in solution. In parallel there is interaction of free proton with pyridine ring and concentration of positively charged ions in solution sharply decreases.

Dependence of specific electric conductivity of aqueous solutions on hPAA:hP4VP molar ratios in time is presented in Fig. 2. Electric conductivity of water increases with time almost for all ratios of the hydrogels. However, the character of the parameter change is different for various ratios of the hydrogels. It should be noted that there is an appearance of the areas of minimum and maximum electric conductivity. Minimum electric conductivity is observed in the presence of only polybasis and polyacid. Maximum values of the specific electric conductivity are reached at $48 \mathrm{~h}$ of remote interaction at hydrogels ratio 17\% hPAA- $83 \% \mathrm{hP} 4 \mathrm{VP}$. As seen from Fig. 2 , there is an increase of the electric conductivity with time, wherein significant increase of the parameter for intergel pairs is observed during $6 \mathrm{~h}$ of hydrogels interaction in an aqueous medium. This is due to the transition of the initial polymer hydrogels of polyacrylic acid and poly-4-vinypyridine into highly ionized state due to mutual activation during their remote interaction.

Change of $\mathrm{pH}$ of an aqueous solution is presented in Fig. 3. As seen from the obtained results, there is an increase of $\mathrm{pH}$ values with time of remote interaction. The increase of $\mathrm{pH}$ is due to the binding of the cleaved proton from the carboxyl group by vinylypyridine in the result of what process of protoning of the heteroatom of the ring occurs. This is evidenced by maximums at the ratio $33 \% \mathrm{hPAA}: 67 \% \mathrm{hP} 4 \mathrm{VP}$, which are corresponded to remote interaction time of $24 \mathrm{~h}$ and $48 \mathrm{~h}$. Minimum values of $\mathrm{pH}$ are observed in the presence of only polyacid. This is due to appearance of charged ions $\left(\mathrm{H}^{+}, \mathrm{OH}^{-}\right)$and groups $(-$ $\mathrm{COO}^{-}, \equiv \mathrm{NH}^{+}$). Maximums of $\mathrm{pH}$ point to the fact that the dissociation rate of $-\mathrm{COOH}$ groups is lower than the protonization rate of vinylpyridine heteroatom. This phenomenon points to the process of ionization of the basic polymer hydrogel. Consequently, both polymer hydrogels are transferred into highly ionized state undergoing mutual activation. 


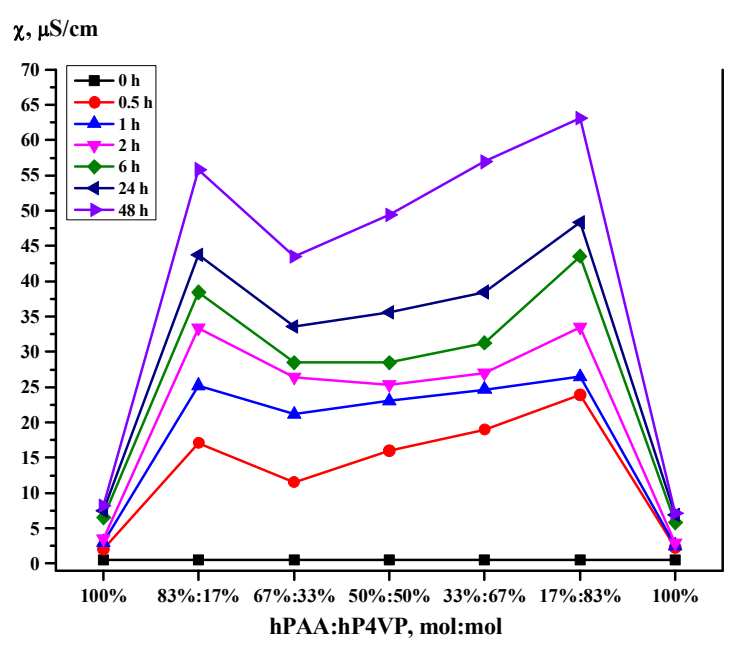

Fig. 2. Dependence of specific electric conductivity on hPAA and $\mathrm{hP} 4 \mathrm{VP}$ hydrogels ratios in time

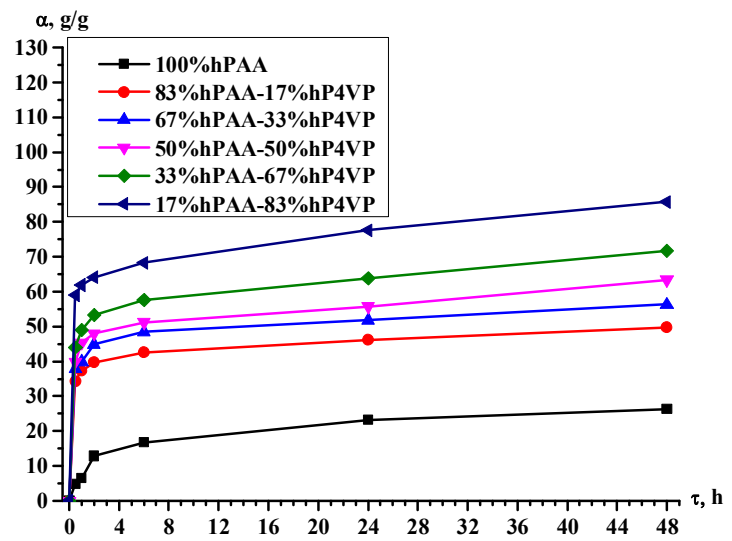

Fig. 4. Dependence of hPAA swelling degree in time in the presence of hP4VP

Dependence of swelling degree of hPAA in time in the presence of hP4VP is presented in Fig. 4. Increase of swelling of polymer hydrogel of polyacrylic acid occurs for all hydrogels ratios in the intergel system hPAAhP4VP. With the increase of the share of poly-4vinylpyridine hydrogel the swelling degree slightly increases. The highest values of the swelling degree of PAA hydrogel are observed at the ratios 33\% hPAA$67 \%$ hP4VP and 17\%hPAA-83\%hP4VP. Maximum swelling of PAA hydrogel occurs at the ratio 17\% hPAA$83 \% \mathrm{hP} 4 \mathrm{VP}$ at $48 \mathrm{~h}$ of remote interaction of the polymers. Minimum values of swelling degree are observed in the presence of only polyacid, which is due to absence of the phenomenon of mutual activation.

Dependence of swelling degree of hP4VP in time in the presence of hPAA is presented in Fig. 5. As seen from the figure, there is a slight increase (due to the fact

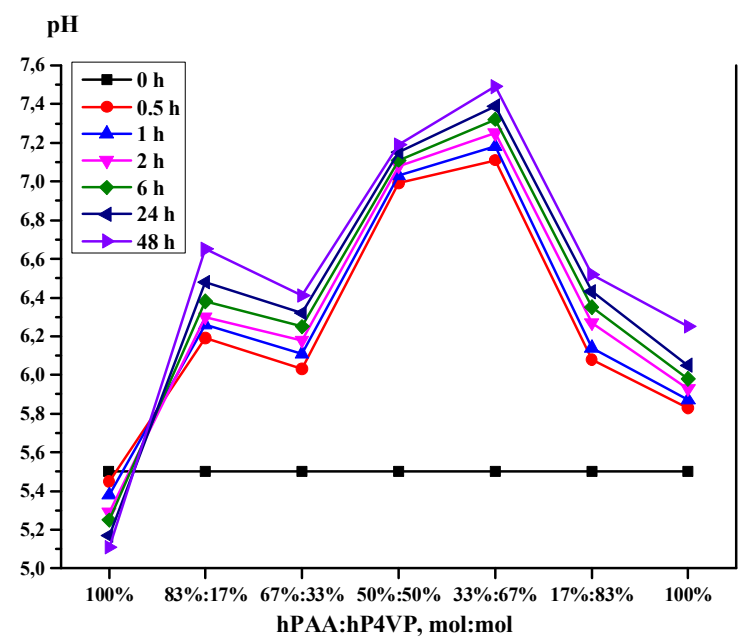

Fig. 3. Dependence of pH from hPAA and hP4VP hydrogels ratios in time

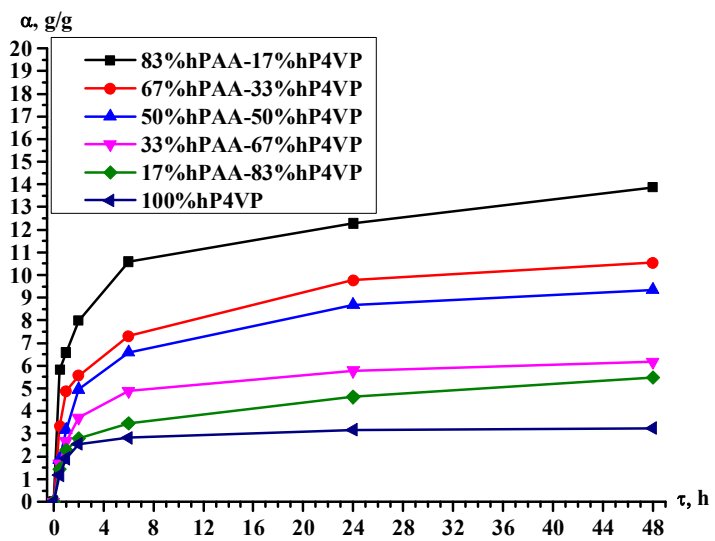

Fig. 5. Dependence of hP4VP swelling degree in time in the presence of hPAA

that vinylpyridine is a weak polybasis) of swelling degree of the individual polymer hydrogel of poly-4vinylpyridine. Similarly to acid hydrogel (Fig. 3), the polybasis swelling increases with the increase of the share of the second hydrogel in the solution. Maximum swelling of the hP4VP is observed at the ratio $83 \% \mathrm{hPAA}$ $17 \% \mathrm{hP} 4 \mathrm{VP}$ at $48 \mathrm{~h}$.

Obtained data on specific electric conductivity, $\mathrm{pH}$ and swelling degree shows that electrochemical and volumegravimetric properties of the PAA and P4VP hydrogels are significantly changed during remote interaction.

\subsection{Sorption of Neodymium and Praseodymium Ions}

Neodymium and praseodymium nitrates are present in solution in dissociated state. Dissociation of the nitrate 
occurs in 3 stages, where constant of $1^{\text {st }}$ stage is much higher than constants of $2^{\text {nd }}$ and $3^{\text {rd }}$ ones. In this regard intergel system binds dissociated REM ions in accordance with different mechanisms. Nitrates of the REM formed in first stage are bound by ionic mechanism. Products of second and third stage are bound due to coordination. In solution in addition to present $-\mathrm{COO}^{-}$and $\mathrm{H}^{+}$ions there are ions formed at three-stage lanthanum dissociation.

The following chemical reactions occur:

1) Lanthanum nitrate dissociation in parallel with carboxyl groups dissociation;

2) Mutual activation of hydrogels due to proton binding by poly-4-vinylpyridine;

3) Sorption of lanthanum ions by hydrogels.

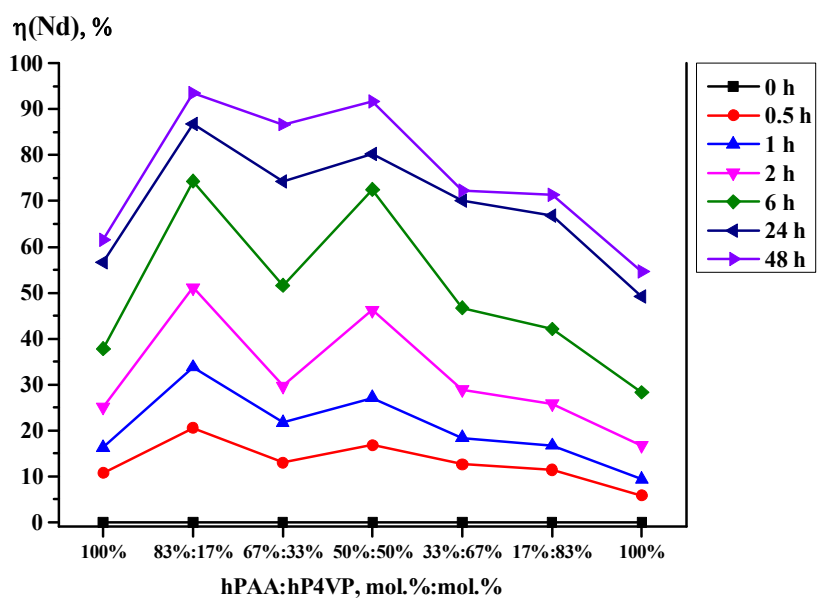

Fig. 6. Dependence of extraction degree of neodymium ions on hPAA and hP4VP hydrogels ratios in time

It is seen from Fig. 6 , the sorption degree at $24 \mathrm{~h}$ of remote interaction in the intergel pairs $83 \% \mathrm{hPAA}-$ $17 \% \mathrm{hP} 4 \mathrm{VP}, 50 \% \mathrm{hPAA}-50 \% \mathrm{hP} 4 \mathrm{VP}$ is 86.8 and $80.3 \%$, respectively. The further increase (up to $48 \mathrm{~h}$ ) is slight, what points to the reaching to equilibrium state by the intergel system. The extraction degree is 93.5 and $91.7 \%$ for the ratios $83 \% \mathrm{hPAA}-17 \% \mathrm{hP} 4 \mathrm{VP}$ and $50 \% \mathrm{hPAA}-$ $50 \% \mathrm{hP} 4 \mathrm{VP}$.

Polymer chain binding degree (in relation to neodymium ions) of the intergel system hPAA-hP4VP is presented in Fig. 7. Share of the active links (which participate in sorption process) is not very high in case with individual hydrogels - at $6 \mathrm{~h}$ of interaction $30.4 \%$ of links are active for $\mathrm{hPAA}$ and $22.6 \%$ are active for $\mathrm{hP} 4 \mathrm{VP}$, at $48 \mathrm{~h}$ the share increases up to $50.2 \%$ for hPAA and $45.6 \%$ for hP4VP. Mutual activation of the polymer hydrogels in intergel pairs provides significant increase of the parameter - at $6 \mathrm{~h}$ of interaction at the ratios $83 \% \mathrm{hPAA}-17 \% \mathrm{hP} 4 \mathrm{VP}$ and $50 \% \mathrm{hPAA}-50 \% \mathrm{hP} 4 \mathrm{VP}$ the binding degree is 60.6 and $58.8 \%$, respectively. Further

\subsubsection{Study of neodymium ions sorption by intergel system hPAA-hP4VP}

Fig. 6 represents dependence of extraction degree of neodymium ions of the intergel system hPAA-hP4VP on hydrogels molar ratios in time. There is an increase of the parameter with time for all ratios (including individual hydrogels of PAA and P4VP). First six hours of interaction provide the most intense sorption of the metal. Sorption degree for individual hPAA and hP4VP is 37.8 and $28.3 \%$, respectively. As seen from the data, the areas of high ionization are the ratios $83 \% \mathrm{hPAA}-17 \% \mathrm{hP} 4 \mathrm{VP}$, $50 \% \mathrm{hPAA}-50 \% \mathrm{hP} 4 \mathrm{VP}$. At $6 \mathrm{~h}$ of interaction sorption degree is 74.3 and $72.5 \%$, respectively.

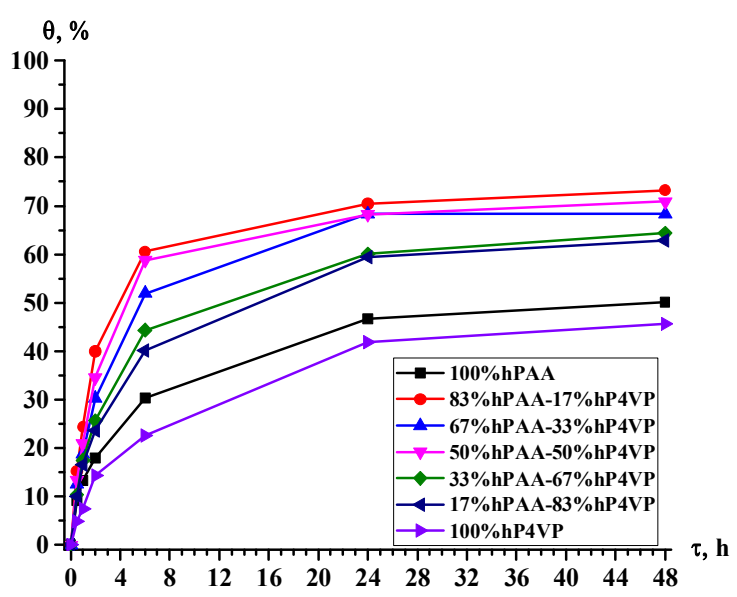

Fig. 7. Dependence of polymer chain binding degree (in relation to neodymium ions) of intergel system hPAAhP4VP on time

additional activation provides increase of the share of active links up to $73.2 \%$ for the ratio $83 \% \mathrm{hPAA}-$ $17 \% \mathrm{hP} 4 \mathrm{VP}$ and $70.9 \%$ for the ratio $50 \% \mathrm{hPAA}-$ $50 \% \mathrm{hP} 4 \mathrm{VP}$.

\subsubsection{Study of praseodymium ions sorption by intergel system hPAA-hP4VP}

Sorption degree (in relation to praseodymium ions) of the intergel system hPAA-hP4VP is presented in Fig. 8. Absence of phenomenon of mutual activation in case of sorption of praseodymium ions by individual hydrogels point to the fact that electrochemical equillibrium is reached rather fast, overwhelming majority of the REM ( $58.5 \%$ for hPAA and $51.7 \%$ for hP4VP) is sorbed during $24 \mathrm{~h}$ of interaction, wherein most amount of it ( $39.9 \%$ for hPAA and $30.4 \%$ for hP4VP) is sorbed during $6 \mathrm{~h}$. Optimal conformation for sorption of praseodymium is formed in the following intergel pairs: $67 \% \mathrm{hPAA}-33 \% \mathrm{hP} 4 \mathrm{VP}$ and $50 \% \mathrm{hPAA}-50 \% \mathrm{hP} 4 \mathrm{VP}$. The highest sorption of the metal is observed at these ratios. 
During $6 \mathrm{~h} 75.1 \%$ of the metal is sorbed by $67 \% \mathrm{hPAA}-$ $33 \% \mathrm{hP} 4 \mathrm{VP}$ and $77.7 \%$ for $50 \% \mathrm{hPAA}-50 \% \mathrm{hP} 4 \mathrm{VP}$. At $48 \mathrm{~h}$ of remote interaction sorption degree of neodymium ions is $91.8 \%$ for $67 \% \mathrm{hPAA}-33 \% \mathrm{hP} 4 \mathrm{VP}$ and $93.6 \%$ for $50 \%$ hPAA- $50 \% \mathrm{hP} 4 \mathrm{VP}$.

Fig. 9 represents polymer chain binding degree in relation to praseodymium ions of intergel system hPAAhP4VP. Share of active links during sorption in case with individual hydrogels of PAA and P4VP does not exceed $55 \%(52.1 \%$ for hPAA and $48.3 \%$ for hP4VP). The areas of maximum ionization of links are the ratios: 67\%hPAA-33\%hP4VP and 50\%hPAA-50\%hP4VP. The maximum values of binding degree are $72.6 \%$ for $67 \% \mathrm{hPAA}-33 \% \mathrm{hP} 4 \mathrm{VP}$ and $75.4 \%$ for $50 \% \mathrm{hPAA}-$ $50 \% \mathrm{hP} 4 \mathrm{VP}$ at $48 \mathrm{~h}$ of remote interaction. It should be noted that at the ratio $50 \% \mathrm{hPAA}-50 \% \mathrm{hP} 4 \mathrm{VP}$ the equilibrium is almost reached at $6 \mathrm{~h}$ of interaction (values

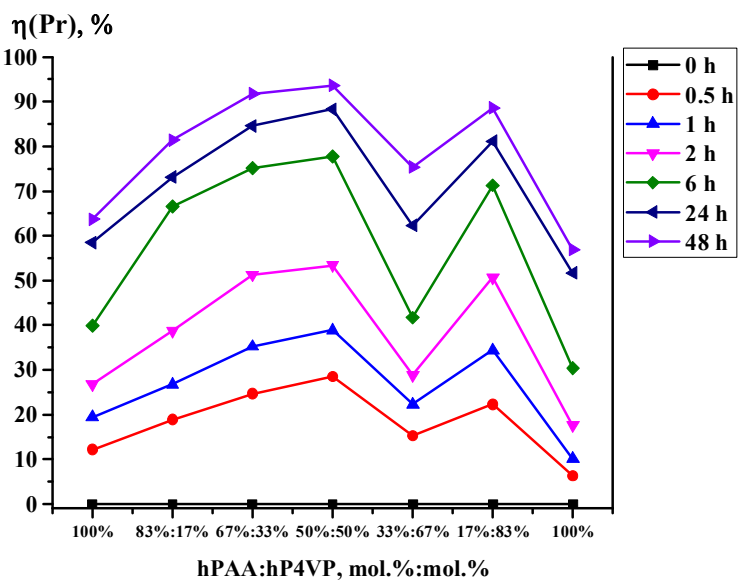

Fig. 8. Dependence of extraction degree of praseodymium ions on hPAA and hP4VP hydrogels ratios in time

\section{Conclusions}

As seen from the obtained data, there are significant changes in electrochemical, conformational and sorption properties of polymer hydrogels of polyacrylic acid and poly-4-vinylpyridine as the result of polymer macromolecules mutual activation. Such increase is the direct result of the transition of the polymers into highly ionized state due to the mutual activation during their remote interaction.

Maximum extraction of neodymium occurs at the ratio $83 \% \mathrm{hPAA}-17 \% \mathrm{hP} 4 \mathrm{VP}$, extraction degree is $93.5 \%$. The highest sorption of praseodymium ions is observed at the ratio $50 \% \mathrm{hPAA}-50 \% \mathrm{hP} 4 \mathrm{VP}$, sorption degree is $93.6 \%$.

The highest values of polymer chain binding degree (in relation to neodymium ions) are observed at the of polymer chain binding degree are: $69.1 \%$ at $6 \mathrm{~h}$; $73.7 \%$ at $24 \mathrm{~h}$ and $75.4 \%$ at $48 \mathrm{~h}$ ).

As known, according to Periodical Table of elements of D.I. Mendeleev destination of the elements determines their properties. With constant charge of ion with increase of serial number there is a decrease of ionic radius. For the selected lanthanoids (neodymium and praseodymium) ionic radius has the following values (charge +3 ; coordination number 6 ): for neodymium 0.983 ; for praseodymium -0.990 . As seen from the values the difference is insignificant. Due to this fact at the simultaneous sorption these elements will interfere each other. Also, it should be noted that different hydrogels ratios with the highest sorption in the intergel system hPAA-hP4VP is due to the different main properties of these ions (atomic radius, polarizability, charge density).

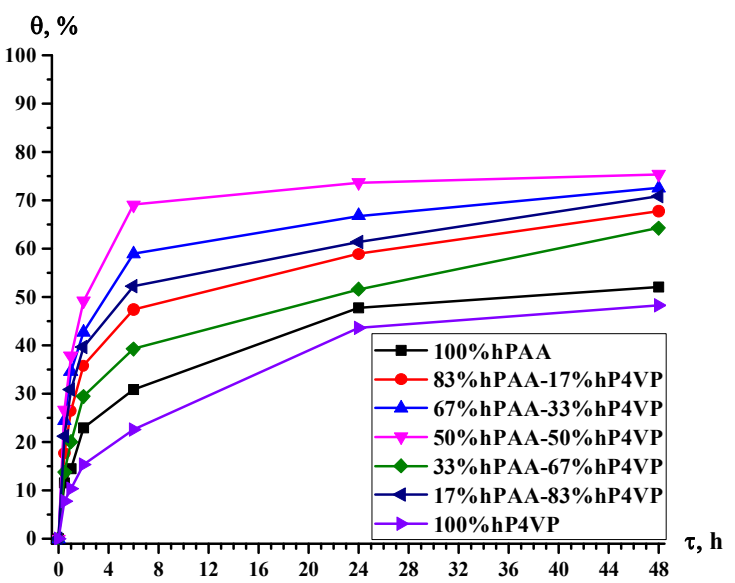

Fig. 9. Dependence of polymer chain binding degree (in relation to praseodymium ions) of intergel system hPAAhP4VP on time

ratio $83 \% \mathrm{hPAA}-17 \% \mathrm{hP} 4 \mathrm{VP}$, binding degree is $73.2 \%$. The maximum values of polymer chain binding degree (in relation to praseodymium ions) are observed at the ratio $50 \% \mathrm{hPAA}-50 \% \mathrm{hP} 4 \mathrm{VP}$, polymer chain binding degree is $75.4 \%$.

The increase of the sorption properties is due to different conformational changes in structure of polymer macromolecules (e.g., unfolding of globe due to repulsion of same-charged ions of internode links of macromolecule) during hydrogels ionization. Concentration of ions in studied intergel system is in direct dependence on swelling rate and hydrogels concentration in water solution. Rates of swelling and deprotonization depend on the nature of hydrogel, crosslinking degree, dispersity and longitudinal size of polymer hydrogels. 


\section{Acknowledgments}

The study was financially supported by the Committee of Science of Ministry of Education and Science of the Republic of Kazakhstan - grant number AP08856668.

\section{References}

[1] Mulder, M. Basic Principles of Membrane Technology; Springer: Netherlands, 1996. https://doi.org/10.1007/978-94-0091766-8

[2] Khaing Z., Troshkina A.: Sorp. Chromatogr. Proc., 2006, 6, 972.

[3] Ion Exchangers; Dorfner, K., Ed.; Walter de Gruyter: Berlin, 1991. https://doi.org/10.1515/9783110862430

[4] Harland, C.E. Ion Exchange: Theory and Practice, $2^{\text {nd }}$ edn.; The Royal Society of Chemistry, 1994.

https://doi.org/10.1039/9781847551184

[5] Alekseeva, S.L.; Bolotin, S.N.; Tsupko, T.G. Sorption of Cr(VI) on AV-17 and EDE-10P Anion Exchangers, KU-2 and KB-4 Cation Exchangers, Activated Charcoal, and Foamed Graphite (STRG) is Studied. J. Appl. Chem. 2007, 80, 376-378.

https://doi.org/10.1134/S107042720703007X

[6] Ergozhin, E.; Begenova, B. Polielektrolity i Kompleksiony; Evero: Almaty, 2010.

[7] Ion Exchange: Highlights of Russian Science; Muraviev, D.; Gorshkov, V.; Warshawsky, A., Eds.; Marcel Dekker: New York, 2000.

[8] Zagorodni, A. Ion Exchange Materials: Properties and Applications, $1^{\text {st }}$ ed.; Elsevier Science, 2006.

[9] Dzhafarov, V.D.; Alyev, N.A.; Guseinov, E.T.; Efendiev, A.A. Synthesis of Polymerizable Oligomers via Cationic Polymerization of $\alpha$-Oxides. Polym. Sci. B, 2008, 50, 83-87.

https://doi.org/10.1134/S156009040803010X

[10] Alexandratos, S.D. Ion-Exchange Resins: A Retrospective from Industrial and Engineering Chemistry Research. Ind. Eng. Chem. Res. 2009, 48, 388-398. https://doi.org/10.1021/ie801242v

[11] Membrane Science and Technology; Osada, Y.; Nakagawa, T., Eds.; Marcel Dekker: New York, 1992.

[12] Zeman, L.; Zydney, A. Microfiltration and Ultrafitration, Principles and Applications; Marcel Dekker: New York, 1996.

[13] Van Reis, R.; Zydney, A. Bioprocess Membrane Technology.

J. Membrane Sci., 2007, 297, 16-50.

https://doi.org/10.1016/j.memsci.2007.02.045

[14] Alimbekova, B.T.; Korganbayeva, Zh.K.; Himersen, H.J.; Kondaurov, R.G.; Jumadilov, T.K. Features of Polymethacrylic Acid and Poly-2-Methyl-5-Vinylpyridine Hydrogels Remote Interaction in an Aqueous Medium. J. Chem. Chem. Eng. 2014, 3, 265-269.

[15] Jumadilov, T. Mutual Activation and High Selectivity of Polymeric Structures in Intergel Systems. Abstracts of Papers, Third International Caucasian Symposium on Polymers \& Advanced Materials, Tbilisi, Georgia, Sept 1-4, 2013; Iv. Javakhishvili Tbilisi State University: Tbilisi, 2013; p 43.

[16] Jumadilov, T. Electrochemical and Conformational Behaviour of Intergel Systems Based on the Rare Crosslinked Polyacid and Polyvynilpyrydines. Book of Abstracts, International Conference of Lithuanian Chemical Society "Chemistry and Chemical
Technology", Lithuania, Kaunas, 2014; Kaunas University of Technology: Kaunas, 2014, pp 226-229.

[17] Jumadilov, T.; Abilov, Zh.; Kondaurov, R.; Himersen, H.; Yeskalieva, G.; Akylbekova, M.; Akimov, A. Influence of Hydrogels Initial State on their Electrochemical and VolumeGravimetric Properties in Intergel System Polyacrylic Acid Hydrogel and poly-4-Vinylpyridine Hydrogel. Chem. Chem. Technol. 2015, 9, 459-462. https://doi.org/10.23939/chcht09.04.459 [18] Jumadilov T., Akimov A. Eskaliyeva G., Kondaurov R. Features of Polyvalent Metals Sorption by Intergel Systems. Book of Abstracts. VIII International Scientific-Technical Conference Advance in Petroleum and Gas Industry and Petrochemistry, Lviv, Ukraine, May 16-21, 2016; Lviv Polytechnic Publishing House: Lviv, 2016, p 68.

[19] Jumadilov, T.; Kondaurov, R.; Abilov, Zh.; Grazulevicius, J.V.; Akimov, A.A. Influence of Polyacrylic Acid and poly-4-

Vinylpyridine Hydrogels Mutual Activation in Intergel System on their Sorption Properties in Relation to Lanthanum (III) Ions. Pol. Bul. 2017, 74, 4701-4713. https://doi.org/10.1007/s00289-0171985-3

[20] Suberlyak, O.; Mel'nyk, Y.; Skorokhoda, V. Regularities of Preparation and Properties of Hydrogel Membranes. Mater. Sci. 2015, 50, 889-896. https://doi.org/10.1007/s11003-015-9798-8 [21] Grytsenko, O.; Suberlyak, O.; Moravskyi, V.; Gayduk, A. Investigation of Nickel Chemical Precipitation Kinetics. East-Eur. J. Enterpr. Technol. 2016, 1, 26-31. https://doi.org/10.15587/17294061.2016.59506

[22] Semenyuk N., Kostiv U., Suberlyak O., Skorokhoda V.

Peculiarities of Filled Porous Hydrogels Production and Properties.

Chem. Chem. Technol. 2013, 7, 95-99.

https://doi.org/10.23939/chcht07.01.095

[23] Jumadilov, T. Effect of remote interraction of polymeric hydrogels in innovative technology. Ind. Kazakhstan, 2011, 2, 7072.

[24] Bekturov, E.; Suleimenov, I. Polimernie Hydrogeli; Nauka: Moskwa, 1998.

[25] Bekturov, E.; Jumadilov T. Izv. Nats. Akad. Nauk Respubliki Kazakhstan, Ser. Chem. 2010, 3, 86.

[26] Jumadilov, T.; Kondaurov, R.; Imangazy, A.; Myrzakhmetova, N.; Saparbekova, I. Phenomenon of Remote Interaction and Sorption Ability of Rare Cross-linked Hydrogels of Polymethacrylic Acid and Poly-4-vinylpyridine in Relation to Erbium Ions. Chem. Chem. Technol. 2019, 13, 451458.

https://doi.org/10.23939/chcht13.04.451

[27] Jumadilov, T.; Shaltykova, D.; Suleimenov, I. Anomalous Ion Exchange Phenomenon. Book of Abstracts, Austrian-Slovenian Polymer Meeting. Bled, Slovenia, Apr 3-5, 2013; p 51.

[28] Praktikum po Phyziko-Khimicheskim Metodam Analiza; Petruhin, O., Eds.; Khimia: Moskwa, 1987.

Received: January 20, 2020 / Revised: February 02, 2020 / Accepted: June 12, 2020

\section{АНОМАЛЬНА СОРБЦІЯ ЙОНІВ НЕОДІМУ I ПРАЗЕОДІМІЮ ІНТЕРГЕЛОВОЮ СИСТЕМОЮ ГІДРОГЕЛЬ ПОЛІАКРИЛОВОЇ КИСЛОТИ - ПОЛІ- 4-ВІНІЛПІРИДИН}

Анотація. Вивчені сорбиійні властивості (ступінь сорбиії, ступінь зв'язування полімерних ланиююгів) інтергельної системи гідрогель поліакрилової кислоти (hPAA) - гідрогель полі-4-вінілпіридину (hP4VP) щчодо йонів неодиму та пра- 
зеодіму. Встановлено, що віддалена взаємодія полімерів у міжгелевих парах забезпечує суттєві зміни електрохімічних та об'ємних гравіметричних властивостей. Визначено суттєве збільшення ступеня набухання һPAA при співвідношенні 17\% 17\% мають достатньо високих сорбиійних властивостей - ступінь сорбиї йонів неодиму та празеодіму не перевищує $65 \%$, ступінь зв'язування полімерних ланцюгів не перевищує $55 \%$. Висока йонізачія hPAA та hP4VP завдяки ефекту віддаленої взаємодії забезпечує значне покращення (до $30 \%$ сорбиійних властивостей. Максимальна сорбиія йонів неодиму та празеодіму спостерігається при співвідношенні 83\% hPAA-
17\% становить 93,5\% та 93,6\% відповідно). Найвищі значення ступеня зв'язування полімерних ланщюгів (щодо йонів неодиму та празеодіму) спостерігаються при співвідношенні $83 \%$ РРАA17\% hP4VP ma 50\% $\mathrm{hPA}-50 \%$ hP4VP - ступінь зв'язування становить 73,2\% та 75,4\% відповідно. Показано, шо віддалена взаємодія надає можливості для створення інноваційних сорбиійних технологій для вибіркової сорбиії рідкісноземельних елементів.

Ключові слова: інтергельна система, поліакрилова кислота, полі-4-вінілпіридин, віддалена взаємодія, сорбиія йонів $\mathrm{Nd}^{3+}$ i $\mathrm{Pr}^{3+}$. 